\title{
Low level microwave exposure decreases the number of male germ cells and affect vital organs of Sprague Dawley rats
}

\author{
${ }^{1}$ Usikalu M.R, ${ }^{2}$ Aweda M.A., ${ }^{1}$ Babatunde E.B. and ${ }^{3}$ Awobajo F.O. \\ ${ }^{1}$ Deparment of Physics, Covenant University, Ota, Ogun State. \\ ${ }^{2}$ Department of Radiation Biology and Radiotherapy, College of Medicine, University of \\ Lagos, Lagos \\ ${ }^{3}$ Department of Physiology, College of Medicine, University of Lagos.
}

\begin{abstract}
The effects of $2.45 \mathrm{GHz}$ microwave (MW) radiation on the vital tissues of Sprague Dawley rats were investigated. The various tissues assessed through histopathological assay were liver, kidney, heart, testis, ovary, fallopian tube, prostate, seminal vesicle and epididymis. The animals were exposed to various level of Specific Absorption Rate (SAR) which were 0 (control), 0.48 , $0.95,1.43,1.91$ and $2.39 \mathrm{~W} / \mathrm{kg}$ using the microwave generator, model ER660E, Serial No MX704CCR from Toshiba UK Ltd for maximum period of ten minutes. From the results it was observed that the kidney and ovary were the most affected tissues in the female animals exposed to $2.45 \mathrm{GHz} \mathrm{MW}$ radiation when compared to the control. Hyperchromasia was observed in the ovary of the animals exposed to MW radiation. Vascular/glomerular congestion, interstitial spaces hemorrhage and tubular cells cloudiness was observed in the kidney. In the male animals, the testis and liver were the most affected organs when compared with control. There was reduction in the number of germ cells and cell disorganization observed from the testis of exposed group. The degree of reduction in the number of the germ cells varies with SARs, highest reduction was observed in the group $\mathrm{V}$ exposed to $2.39 \mathrm{~W} / \mathrm{kg}$ which suggest that $\mathrm{MW}$ radiation has the potential to affects male fertility adversely. Oodema, cloudiness, glomeruli congestion was observed in the liver. There is no significant proof that the microwave radiation at this study frequency produces pathologic effects on the tissue studied except for the decrease in the number of germ cells and modification of some organs.
\end{abstract}

Keywords: $2.45 \mathrm{GHz}$ microwave radiation, histopathology, male germ cell, liver, kidney, testis, ovary,

\section{INTRODUCTION}

Radio frequency (RF) and microwave radiation are non-ionizing electromagnetic radiations present in the environment with possible health risk. Increased exposure of RF electromagnetic field produced by the appliances used in the telecommunications, industry and medicine may lead to biological effects. There has been a growing concern among the public regarding the potential human health hazard of exposure to this radiation (Moulder, 1999). Studies on the biological effects of microwaves reveal several areas of established effects and mechanisms on the one hand and speculative effects on the other. There are known thermal and athermal interaction mechanisms of microwaves with biological systems. The thermal effect is well understood where the temperature of the biological material increases considerably; the temperature rise is determined by equating the rate at which energy is supplied to the tissue to the rate at which it flows out. Heat energy is transported away from the biological tissue by conduction, convection and radiation. In most cases, the cooling by radiation is insignificant. The characteristics of the biological tissue interaction can be assessed by using short enough electromagnetic pulses, so that both convection and radiation cooling can be neglected. In that case, the rate of change of temperature is given by:

$$
\frac{\partial T}{\partial t}=\frac{P}{\rho c}-\frac{T-T_{o}}{\tau}
$$

where $T$ is the temperature, $T_{o}$ is the initial temperature, $t$ is time, $P$ is the power absorbed, $\tau$ is 
the thermal time constant, $\rho$ is the density and $c$ is the specific heat of the tissue. The thermal time constant, $\tau$, is dependent on the geometry. For a sphere,

$$
\tau=\frac{r}{4 K^{\prime}}
$$

where $r$ is the radius and $K^{\prime}$ is the thermal diffusivity (Barnes and $\mathrm{Hu}, 1980$ ). For very short pulses, all the losses can be neglected and

$$
\Delta T=\frac{P t}{\rho c}
$$

The most important of these are the changes in biochemical reaction rates, which in turn affect a large number of physiological functions (Yariv, 1985). Other bioeffects are the physiological and proliferation phenomena in various enzymes, cells, tissues, organs and organisms. Typical biochemical reactions can be described by an equation of the form:

$$
\frac{d[S]}{d t}=-k[S]
$$

where $[S]$ is the concentration of the material undergoing the chemical reaction, $t$ is the time and $k$ is the reaction rate constant (Kenneth, 1984). $k$ is often given by:

$$
k=\frac{k_{B} T}{h} \exp \left(\frac{+\Delta H^{\prime}-T \Delta S^{\prime}}{R T}\right)
$$

where $k_{B}$ is the Boltzmann constant, $T$ is the absolute temperature, $H^{\prime}$ is the enthalpy of activation, $S^{\prime}$ is the entropy of activation, $h$ is Planck's constant, $R$ is the gas constant (Johnson et al., 1974). The significance feature is the reaction constant, $k$, which varies exponentially with temperature, since $\Delta H^{\prime}$ and $T \Delta S^{\prime}$ are large numbers (Johnson et al., 1974). Thus, very small changes in temperature can lead to large changes in chemical reaction rates. The critical temperature is in part controlled by the length of time that the temperature is elevated above $37.5^{\circ} \mathrm{C}$. A rule of thumb suggested by Barnes (1989) to estimate whether significant biological changes are likely is to see if $\Delta T<10^{\circ} \mathrm{C}$ for periods of $10^{-6} \mathrm{~s}$, or $5^{\circ} \mathrm{C}$ for $1 \mathrm{~s}$, or $2^{\circ} \mathrm{C}$ for hours. If the $\Delta T$ is large, then it can be expected to lead to important changes in the biological system.

Also, well-established athermal mechanism of interaction at frequencies below a few tens of $\mathrm{MHz}$ is through electrical stimulation of excitable membranes of nerve and muscle cells (Bernhardt, 1979; Bernhardt, 1983). RF fields can induce currents sufficient to stimulate excitable tissue at frequencies below $1 \mathrm{MHz}$ (Bernhardt, 1979). The threshold current densities for stimulation, and approximate relationships between the strengths of the RF exposure fields and the induced current densities, are available (Bernhardt, 1979; Bernhardt, 1983). Very high field strengths are necessary to reach the stimulation thresholds (electric field strength above $100 \mathrm{kV} \mathrm{m}^{-1}$, magnetic field strength above $1.5 \mathrm{kA} \mathrm{m}^{-1}$ ) (Bernhardt, 1983).

Some experimental results can be interpreted to mean that biological effects may occur without significant changes in temperature well below the stimulation threshold, and should be attributed to non-thermal mechanisms at the molecular level. At low levels, experimental demonstrations include behavioural changes in continuous-wave or modulated fields (Shandala, 1977), altered efflux of calcium from brain tissue exposed to extremely low frequency modulated waves (Blackman, et al., 1979; Blackman, 1980), changes in EEG waves (Takashima, 1979), impaired killing ability of lymphocytes (Lyle, 1983), chromosomal changes in developing mouse sperm cells, changes in intracellular enzyme activity, altered firing rate of molluscan pacemaker neurons (Seaman and Wachtel, 1978), and changes in growth rate of yeast cells. Furthermore, athermal mechanisms are proposed for rectification by cell membranes (Pickard and Rosenbaum, 1978), which has been observed in plant cells at frequencies below $10 \mathrm{MHz}$; vibrational resonance in DNA molecules (Edwards, 1984); and structural transformations from random to coiled configurations in polymeric proteins. Careful measurements recently performed in various laboratories have not confirmed the earlier claims of resonance in DNA molecules (Foster, 1987; Gabril, 1987). In addition, the RF hearing phenomena may be considered athermal or microthermal since the temperature rise is very small (as low as $10^{-5}{ }^{\circ} \mathrm{C}$ ). However, the effects of pulsed microwaves on the auditory system are described by a model in which rapid thermal expansion launches an acoustic wave in the head (Swicord and Poscow, 1986). Toler and Shelton, (1995) reported effects of $435 \mathrm{MHz}$ 
Am. J. Sci. Ind. Res., 2010, 1(3): 410-420

microwaves at SAR of $0.32 \mathrm{~W} / \mathrm{kg} 7$ days/wk, for 21 months on 200 mice were sham-exposed and observed a small, but significantly higher incidence of salivary gland inflammation in the exposed group on histopathological endpoints when compared between chronic radiated and sham-irradiated mice. Other endpoints, including survival times, were virtually identical between the two groups. They concluded that there was little, if any, evidence to suggest a detrimental effect of $435 \mathrm{MHz}$ irradiation. This present work aims at study the effects of $2.45 \mathrm{GHz}$ microwave on vital tissues of the Sprague Dawley rats by assessing pathology on the tissue using histopathological assay.

\section{MATERIALS AND METHODS}

Calibration of Microwave Source: The MW generator model ER660E, Serial No MX704CCR from Toshiba UK Ltd in the Department of Radiation Biology and Radiotherapy, College of Medicine of the University of Lagos was used for irradiation. The detector was the non-interacting thermistor RS 141 , which has a resistance of $4.7 \mathrm{k} \Omega$ at $25{ }^{\circ} \mathrm{C}$. The thermistor was calibrated in a $12 \mathrm{~cm} \times 6 \mathrm{~cm} \times 4 \mathrm{~cm}$ size water phantom with the aid of a digital readout and a mercury-in-glass thermometer as reference. Details of the calibration procedures have been described elsewhere (Aweda et al 2003).

Animal and Sample Preparations: 36 Sprague Dawley rats of each sex, sixteen weeks old weighing 90-130 g, obtained from the Laboratory Animal Centre of the College of Medicine, University of Lagos were used and their care was in conformity with International, National and Institutional guidelines for care and use of laboratory animals in Biomedical Research according to the Canadian Council of Animal Care (Canadian Council, 1984; $\mathrm{NIH}, 1985)$. The rats were fed with standard rat chou obtained from Livestock feeds, Ikeja, Lagos, Nigeria and they had free access to drinking water. They were acclimatized to the laboratory conditions for 5 days and were maintained at the standard conditions of $12 \mathrm{~h} / 12 \mathrm{~h}$ of dark/light cycle. There were six groups of six rats each, 6 males and 6 females served as control at various times. Group I were exposed to $0.48 \mathrm{~W} / \mathrm{kg}$, Group II were exposed to $0.95 \mathrm{~W} / \mathrm{kg}$, Group III were exposed to 1.43 W/kg, Group IV were exposed to $1.91 \mathrm{~W} / \mathrm{kg}$ and group $\mathrm{V}$ were exposed to $2.39 \mathrm{~W} / \mathrm{kg}$. All the groups except the control were exposed to whole body MW radiation.

Determination of Specific Absorption Rate (SAR): Measurement of the SAR was done by inserting the thermistor probe into the animal's rectum during exposure following an earlier method of Guy et al. (1987) with slight modifications to adapt to local requirements. The irradiation chamber surfaces were lagged with water to minimize the reflective properties, which may increase the heating rate (Bren, 1996). The generator was operated at room conditions of $25 \pm 2{ }^{\circ} \mathrm{C}$ and $56 \pm 4 \%$ relative humidity. Exposures were total body with the animal at $12 \mathrm{~cm}$ from the MW antenna and the SARs were obtained using Durney et al, (1980); Mc Ree and Davies (1987) methods.

Histopathological Studies: The abdomens of the animals were carefully opened up and the following organs were removed. For male: testes, epididymis, seminal vesicle, prostate gland, liver, kidney and heart; for female: ovaries along with the fallopian tube, liver, kidney and heart. The sectioning of the tissue was done in the Department of Morbid Anatomy, College of Medicine, University of Lagos. The tissue samples were fixed in $10 \%$ neutral buffered formalin, these were dehydrated with ethanol, and embedded in paraffin. Tissue sections of 5 to $7 \mu \mathrm{m}$ thickness were cut and stained with hematoxylin and eosin ( $H$ \& E) for microscopic examination. The pictures of some of the slides were taken in the Department of Radiobiology, Institute of Modern Physics, Chinese Academy of Sciences, China using RS imager.

\section{RESULTS AND DISCUSSION}

The slides were read by pathologist in the department of Morbid Anatomy, University of Lagos without the knowledge of the exposure SARs level of each slide. No histological or macroscopic alterations were observed in the tissues of the control rats both in male and female, there was normal arrangement of the cells in all the observed tissues. The results obtained from the exposed groups are as follows:

Group I (Female): The uterus, liver and heart were normal no histophatological evidence of cell injury when compared to the control, while the ovary shows thickness of sections (Plate 1q) and the kidney have evidence of foci of lymphocytic aggregate (Plate 1b), however, no evidence of cell death. Group II: The kidney, heart, and uterus were normal no histophatological evidence of cell injury when compared to the control, while the liver cell look cloudy and there are some cells with oodema and the ovary contain numerous follicles of varying sizes (Plate 1r). Group III: The heart shows no significant 
histopathology cell injury compared to the control. While the endometrial, epithelial of the uterus are not histological remarkable. The ovary follicles show increased hyperchromasia, coarse nuclear chromatin and cellular oodema (Plate 1s). The liver shows isolated pyknotic heptacyte, increased mitotic figures, some cells with cloudy cytoplasm and occasional cell with increased hyperchromasia (Plate 1g). The kidney tubules epthilinear lining is cloudy, the glomeruli are congested and cellular oodema (Plate 1c). Group IV: The liver, heart and the uterus are cloudy but no remarkable cellular injury compared to control group. The ovary shows vascular congestion, hyper-chromatic granulocer cell and cellular oodema (Plate 1t). The kidney shows presence of vascular/glomerular congestion, interstitial space hemorrhage and tubular cells are cloudy (Plate 1d). Group V: The heart and the uterus show no remarkable cellular injury compare to control group. The ovary shows evidence of cellular oodema and hyperchromatism in some of the follicles (Plate 1u). The liver shows area of cellular oodema and narrow sinusoids (Plate 1h). The kidney has congestion, interstitial space hemorrhage and cellular oodema (Plate 1e).

Group I (Male): The heart, kidney, prostate and epididymis show no remarkable changes when compared to the control group. Mild reduction of germ cells was observed in the testis and the seminal vesicle (Plate $1 \mathrm{j}$ ) and in liver cellular cloudiness was observed (Plate 1n). Group II: The kidney, heart and prostate were normal no histophatological evidence of cell injury when compared to the control, while testis shows numerous seminofous tubule of germ cell at various stages of maturation. However, there is mild reduction in the number of mature germ cell as compared to control group (Plate 1k). In the epididymis, there is low secretion of germ cell but no obvious damage to cells. Mild reduction in the number of spermatozoa was observed in the seminal vesicle as compared to control group and the liver shows mild oodema with cloudiness (Plate 1n). Group III: The heart, prostate and epididymis are not histologically remarkable. The testis and seminal vesicle show reduction in the number of germ cells (Plate 1j), oodema, cloudiness and glomeruli congestion was observed in the liver and the kidney shows occasional congested vessels (Plate 1n). Group IV and V: The heart, kidney and prostate have no remarkable changes compared to control group. The testis, seminal vesicle and epididymis show reduction in the number of germ cells as compared to control group (Plate 1I), cellular swelling and cloudiness occasional isolated cell necrosis was observed in the liver (Plate $1 \mathrm{~m}$ ).

According to the results of this histology, it was evident that the kidney and ovary were most affected in the entire female exposed to $2.45 \mathrm{GHz} \mathrm{MW}$ radiation. Hyperchromasia was observed in the ovary of the animals exposed to MW radiation and this is a descriptive term referring to the hyperchromatic state of nucleus (elevated chromatin) and this state suggests malignancy. Vascular/glomerular congestion, interstitial spaces hemorrhage and tubular cells cloudiness was observed in the kidney and the chief function of the kidney is to process blood plasma and excrete urine. These functions are important because they play a vital role in the clearance and excretion of xenobiotics including drugs and drug-product, from the body. This situation also suggests renal failure if the radiation SAR is higher than the values used and if exposed for longer time. In the male animals, the testis, and liver were affected organs when exposed to various level of MW radiation when compared with control. The degree of reduction in the number of the germ cells varies with SARs, highest reduction was observed in the group $\mathrm{V}$ exposed to $2.39 \mathrm{~W} / \mathrm{kg}$ which suggest that MW radiation has the potential to affects male fertility adversely. Oodema, cloudiness, glomeruli congestion and occasional cell necrosis was observed in the liver the severity of the pathology was SAR dependent. From this study it can be suggested that the reproductive organs, liver, kidney and reproductive organs are more sensitive to microwave radiation considering the histopathological studies. There is no case of tumor or changes in gland observed in this study apart from the occasional necrosis, which was not reproducible in other slide from the same group observed in the liver of group $\mathrm{V}$ male. This study buttress our earlier observation (Aweda et al., 2010) on the study of male reproductive functions where exposure to this frequency causes decrease in sperm count, reduces sperm motility and increase the weight of liver. The results obtained in this study is in consonance with histopathological reports of Utteridge et al. (2002), Frei et al (1998b), Zook and Simmens (2001) and Anderson et al (2004) that no tumor incidence observed from exposure to microwave radiation.

\section{CONCLUSION:}

There is no significant proof that the radiation at this frequency of study and with various applied SARs 
has damaging effect on the tissue as regards tumour initiation or promotion recognize with light microscopy. However, this does not exclude some cellular damage, mutation that the tissue might incur.
Further works that involve more sensitive microscopy and molecular biology is still going on in our laboratory.
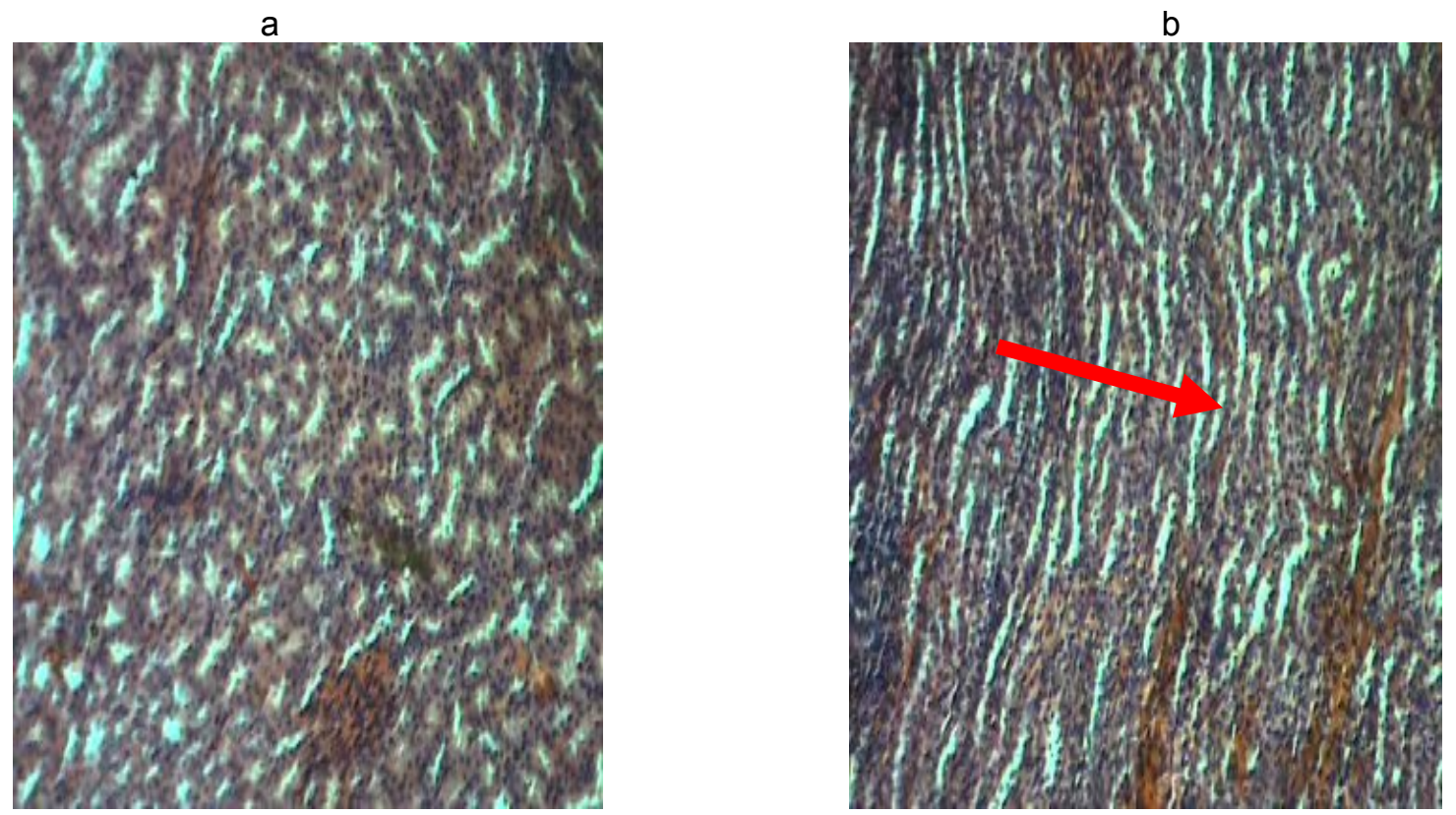

Plate 1a: Micrograph of the kidney of female rats in the control group showing normal arrangement of cells Plate 1b: Micrograph of the kidney of female rats in the group exposed to SAR $0.48 \mathrm{~W} / \mathrm{kg}$ showing foci of cells lymphocytic aggregate $\mathrm{H}$ and $\mathrm{E}$ stain. Mag. x 40
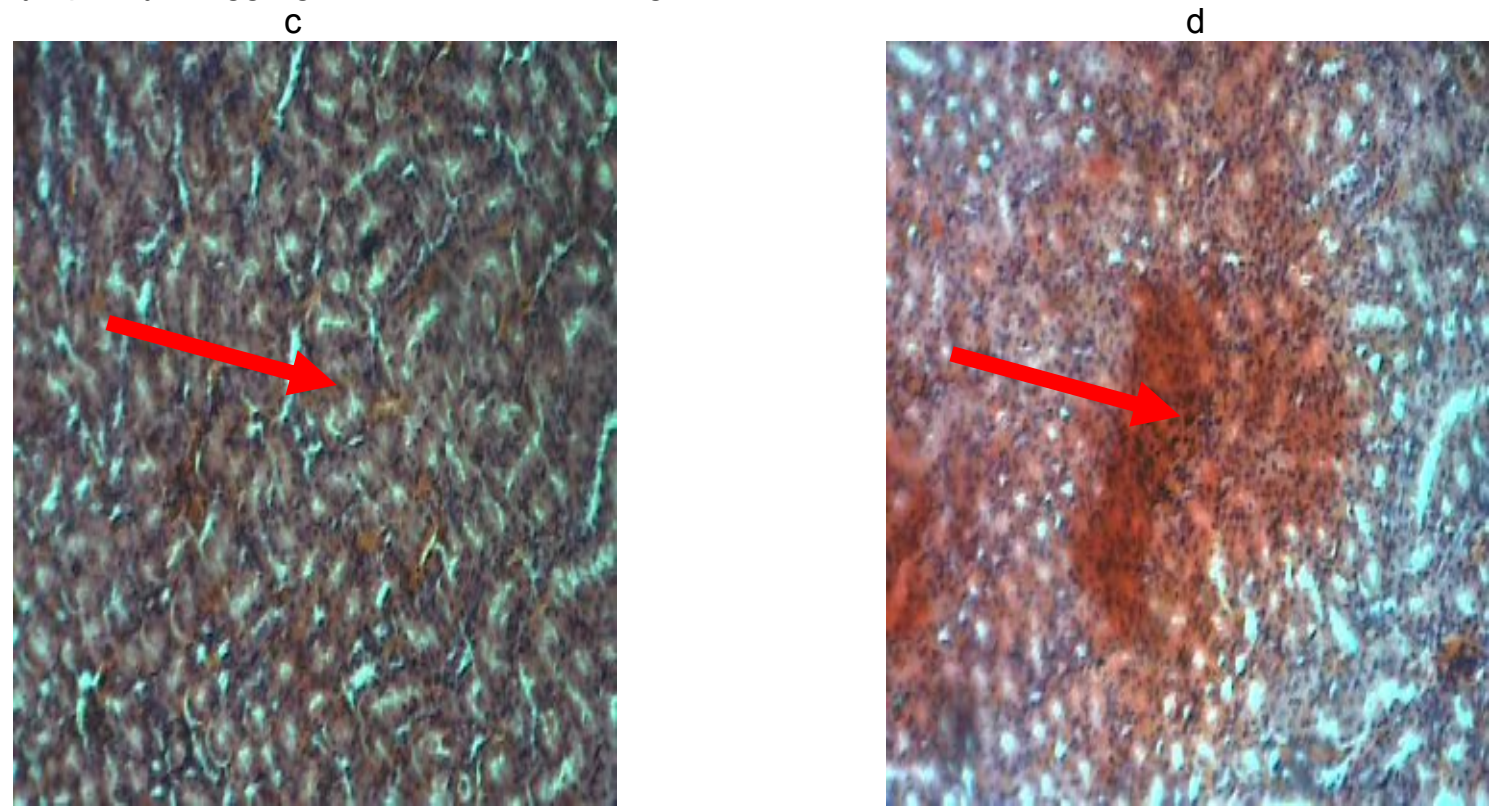

Plate 1c: Micrograph of the kidney of female rats in the group exposed to SAR $1.43 \mathrm{~W} / \mathrm{kg}$ showing cloudy tubules epthilinear lining, glomeruli congestion and cellular oodema

Plate 1d: Micrograph of the kidney of female rats in the group exposed to SAR $1.91 \mathrm{~W} / \mathrm{kg}$ showing glomeruli congestion, interstitial space heamorrage and cellular cloudiness $\mathrm{H}$ and $\mathrm{E}$ stain Mag. $\mathrm{x} 40$ 
Am. J. Sci. Ind. Res., 2010, 1(3): 410-420
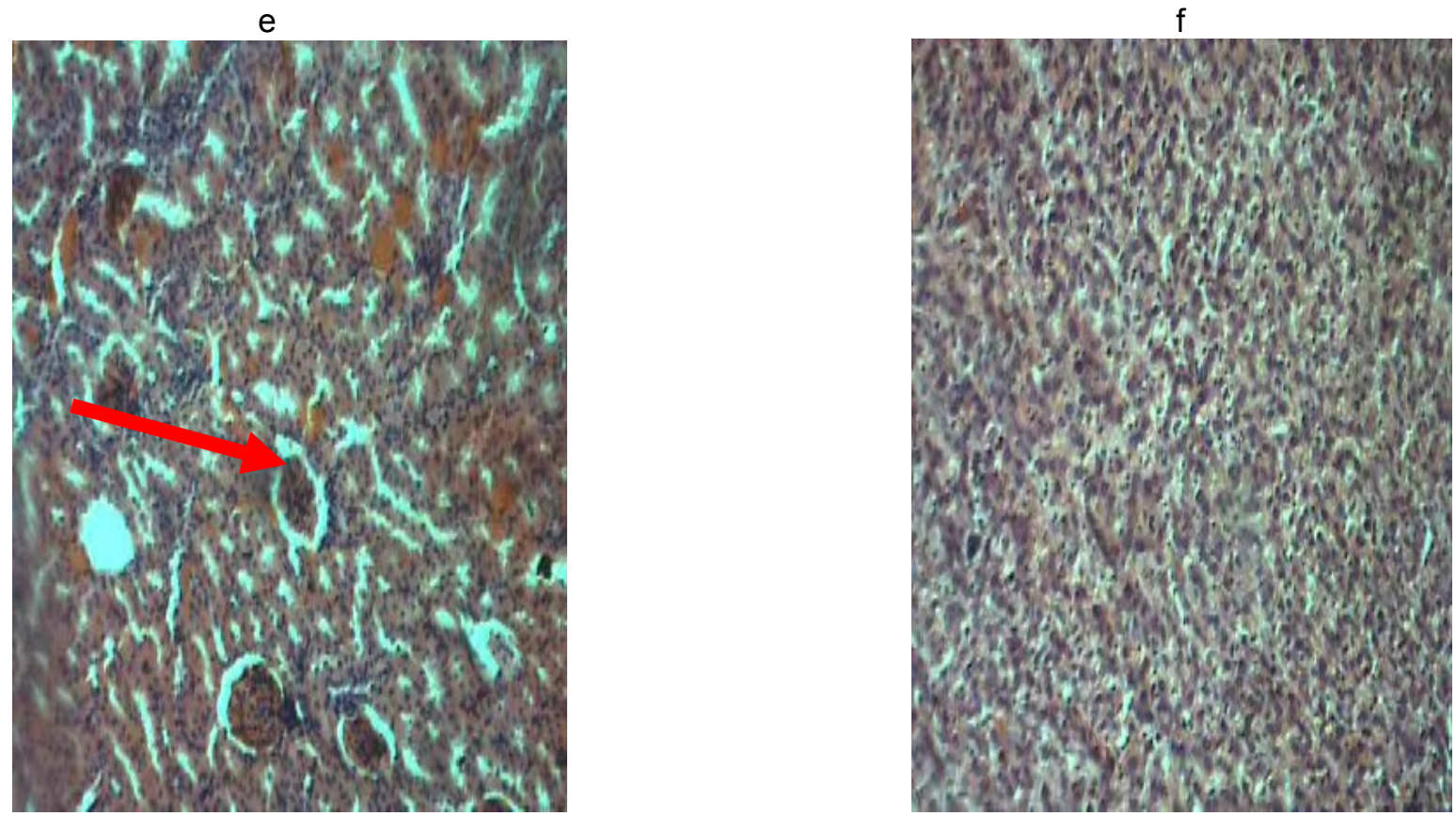

Plate 1e: Micrograph of the kidney of female rats in the group exposed to SAR $2.39 \mathrm{~W} / \mathrm{kg}$ showing glomeruli congestion, interstitial space heamorrage and cellular cloudiness

Plate 1f: Micrograph of the liver of female rats in the control group showing normal arrangement of cells $\mathrm{H}$ and $\mathrm{E}$ stain Mag. $x 40$

g

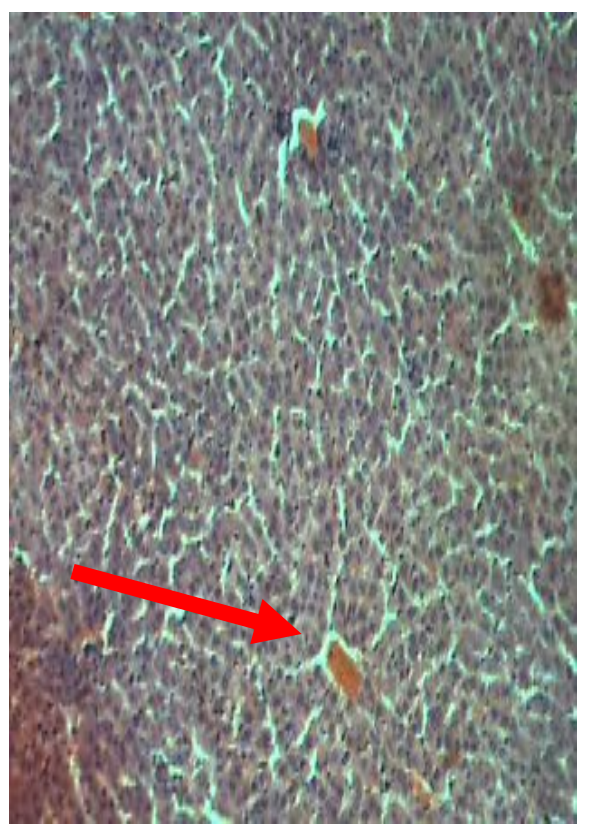

$\mathrm{h}$

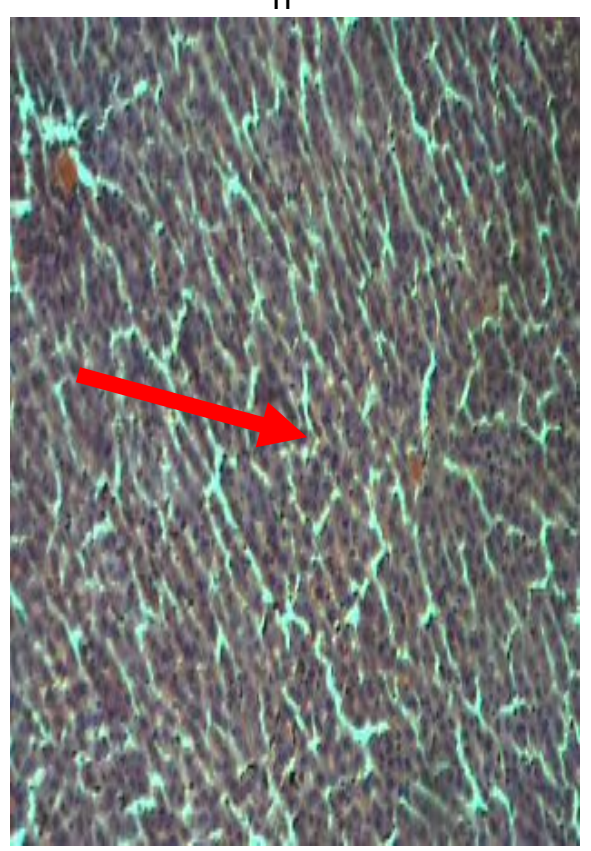

Plate 1g: Micrograph of the liver of female rats in the group exposed to SAR $1.43 \mathrm{~W} / \mathrm{kg}$ showing isolated pyknotic heptacyte, increased mitotic figures, cloudy cytoplasm and increased hyperchromasia Plate 1h: Micrograph of the liver of female rats in the group exposed to SAR $2.39 \mathrm{~W} / \mathrm{kg}$ showing cellular oodema and narrow sinusoids $\mathrm{H}$ and $\mathrm{E}$ stain Mag. $\mathrm{x} 40$ 
Am. J. Sci. Ind. Res., 2010, 1(3): 410-420
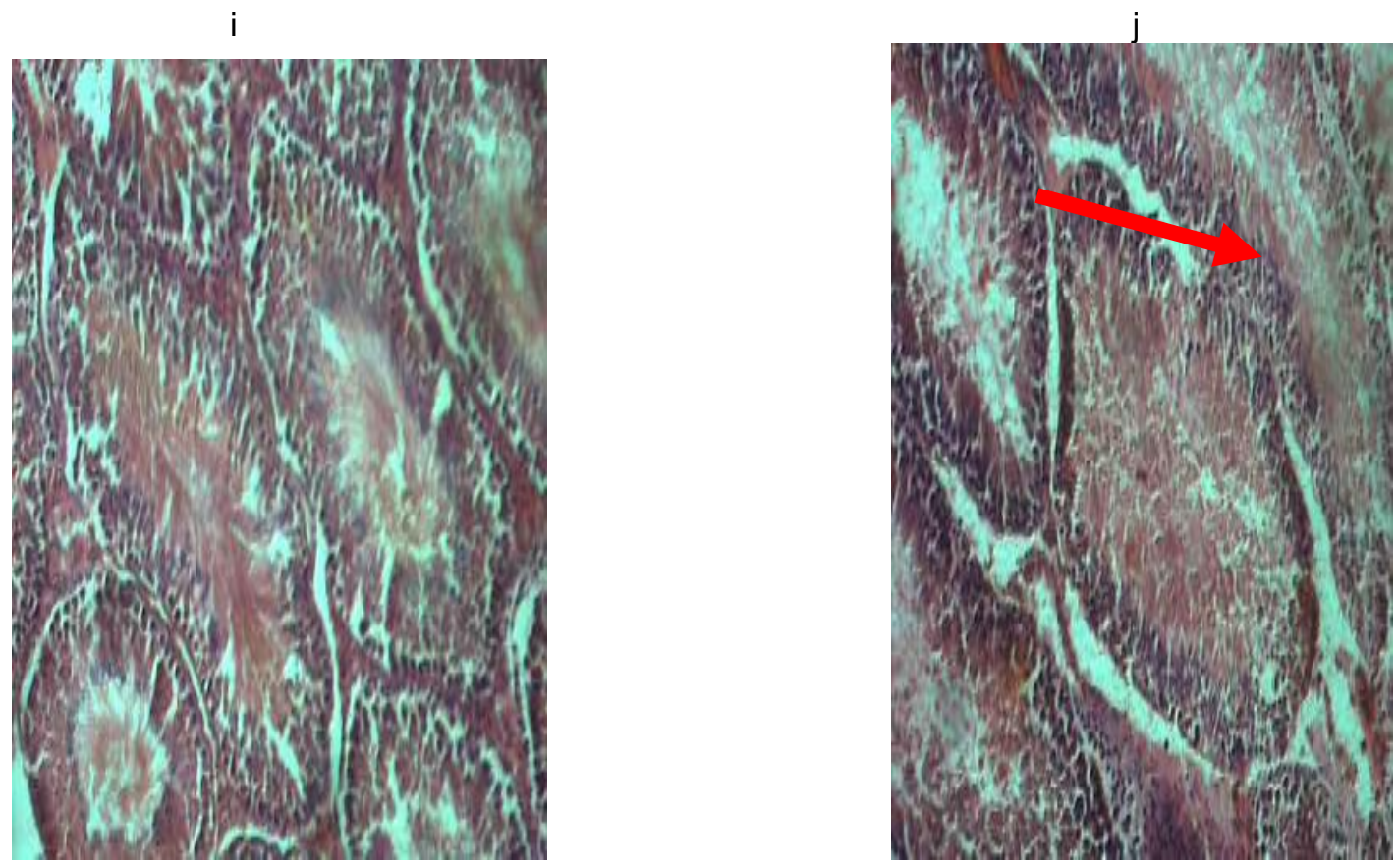

Plate 1i: Micrograph of the testis in the in the control group showing normal arrangement of germ cells Plate 1j: Micrograph of the testis in the in the group exposed to SAR $0.48 \mathrm{~W} / \mathrm{kg}$ showing reduction in the number of germ cells as compared to control $\mathrm{H}$ and $\mathrm{E}$ stain Mag. $\mathrm{x} 40$.
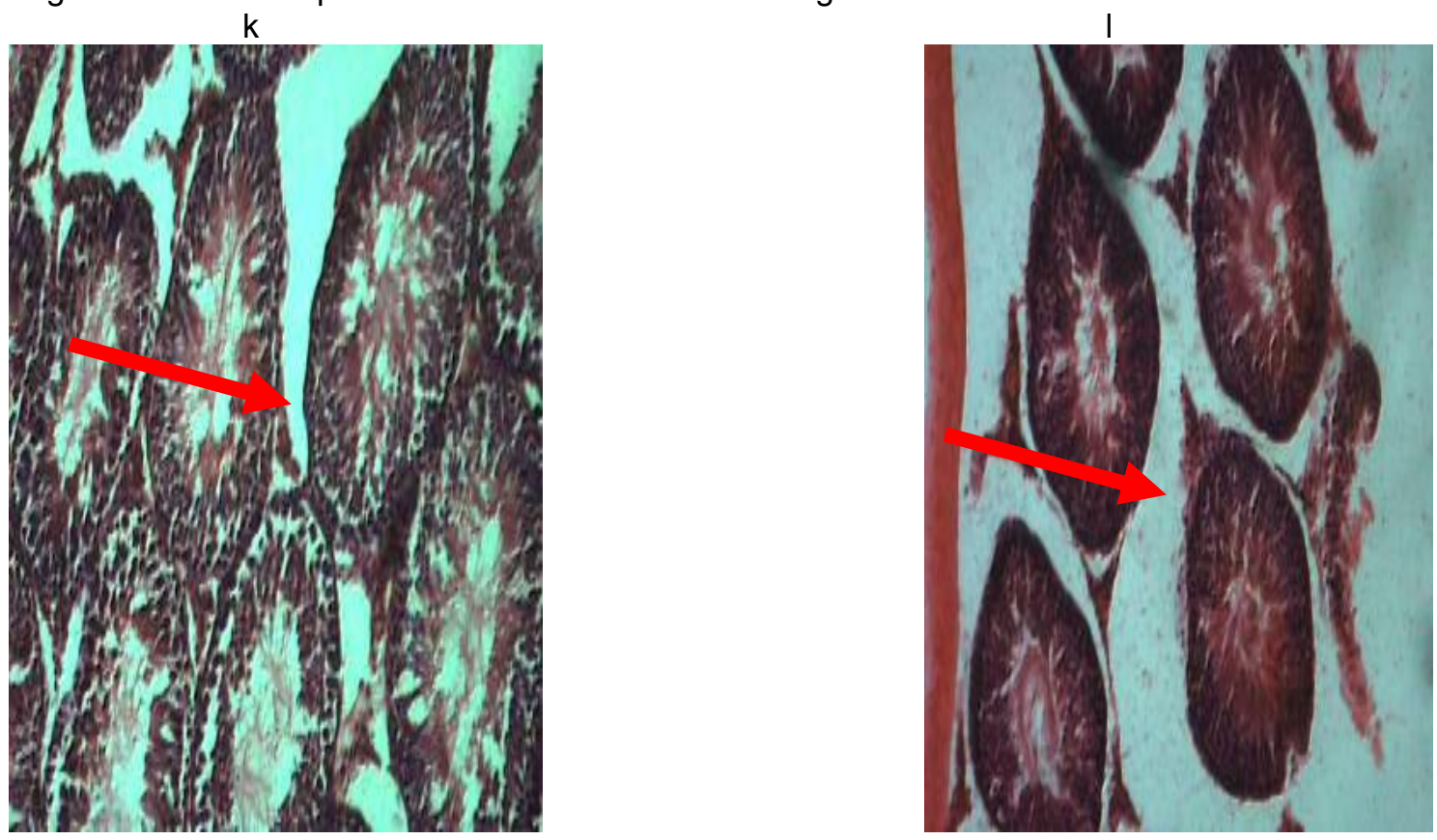

Plate $1 \mathrm{k}$ : Micrograph of the testis in the group exposed to SAR $0.95 \mathrm{~W} / \mathrm{kg}$ showing reduction in the number of germ cells as compared to control

Plate 1I: Micrograph of the testis in the group exposed to SAR $1.43 \mathrm{~W} / \mathrm{kg}$ showing mild reduction in the number of germ cells as compared to control $\mathrm{H}$ and $\mathrm{E}$ stain Mag. $\mathrm{x} 40$ 
Am. J. Sci. Ind. Res., 2010, 1(3): 410-420
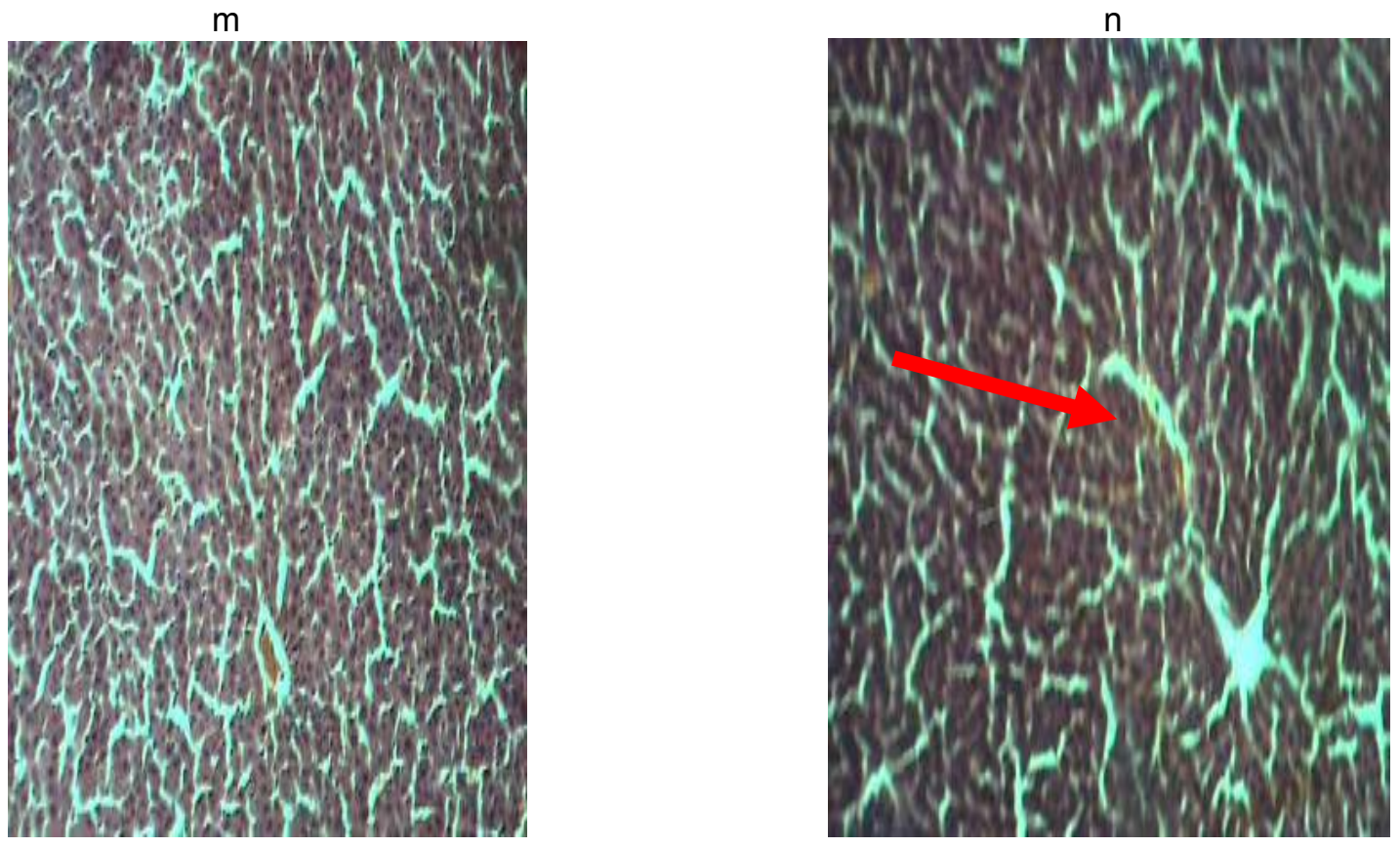

Plate 1m: Micrograph of control male liver showing normal arrangement of cells

Plate 1n: Micrograph of the liver of the male exposed to SAR $0.48,0.95$ and $1.43 \mathrm{~W} / \mathrm{kg}$ showing cloudiness and glomeruli congestion $\mathrm{H}$ and $\mathrm{E}$ stain Mag. $\mathrm{x} 40$
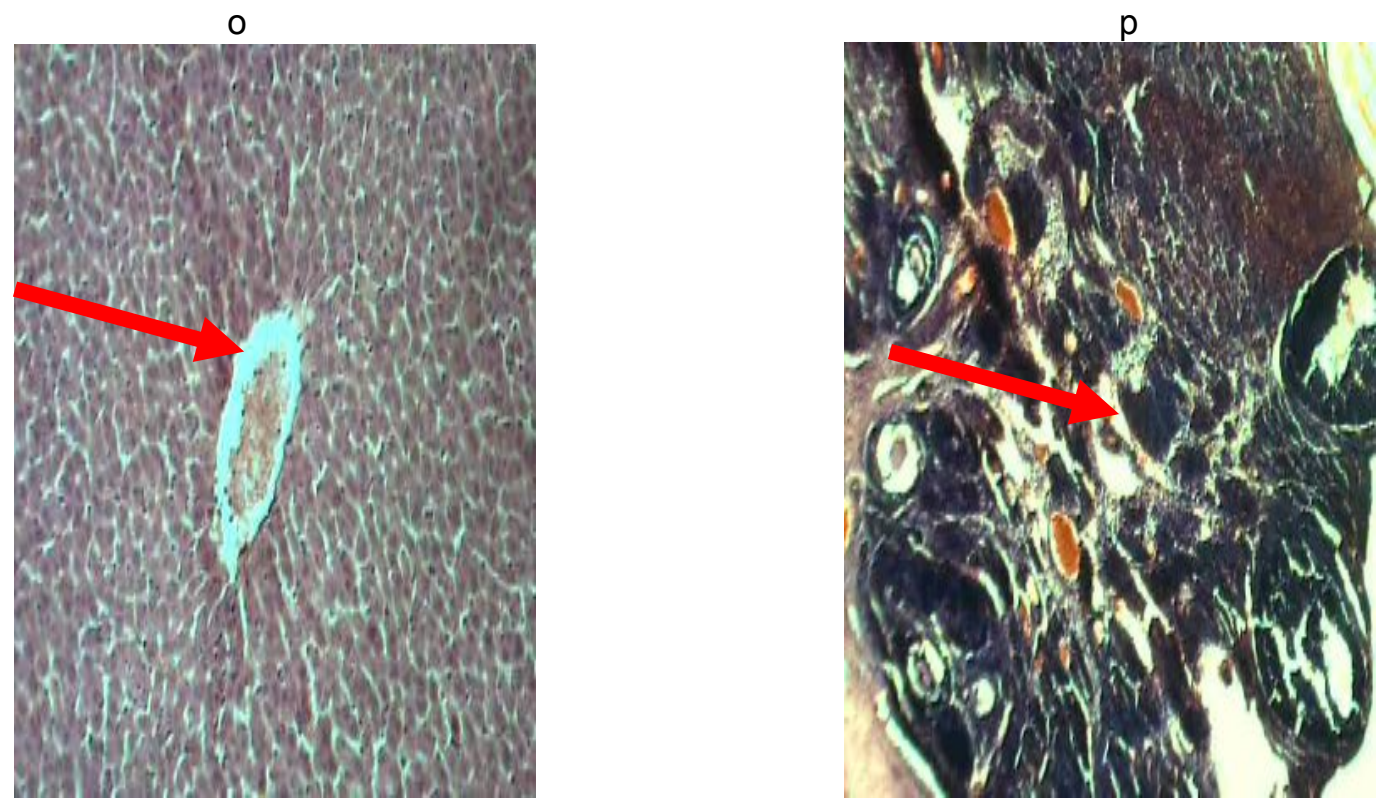

Plate 10: Micrograph of the liver of the male exposed to SAR 1.91 and $2.39 \mathrm{~W} / \mathrm{kg}$ showing cellular swelling, cloudiness and occasional isolated cell necrosis

Plate $1 \mathrm{p}$ : Micrograph of the ovary in the in the control group showing normal arrangement of follicles $\mathrm{H}$ and $\mathrm{E}$ stain Mag. x 40 
Am. J. Sci. Ind. Res., 2010, 1(3): 410-420
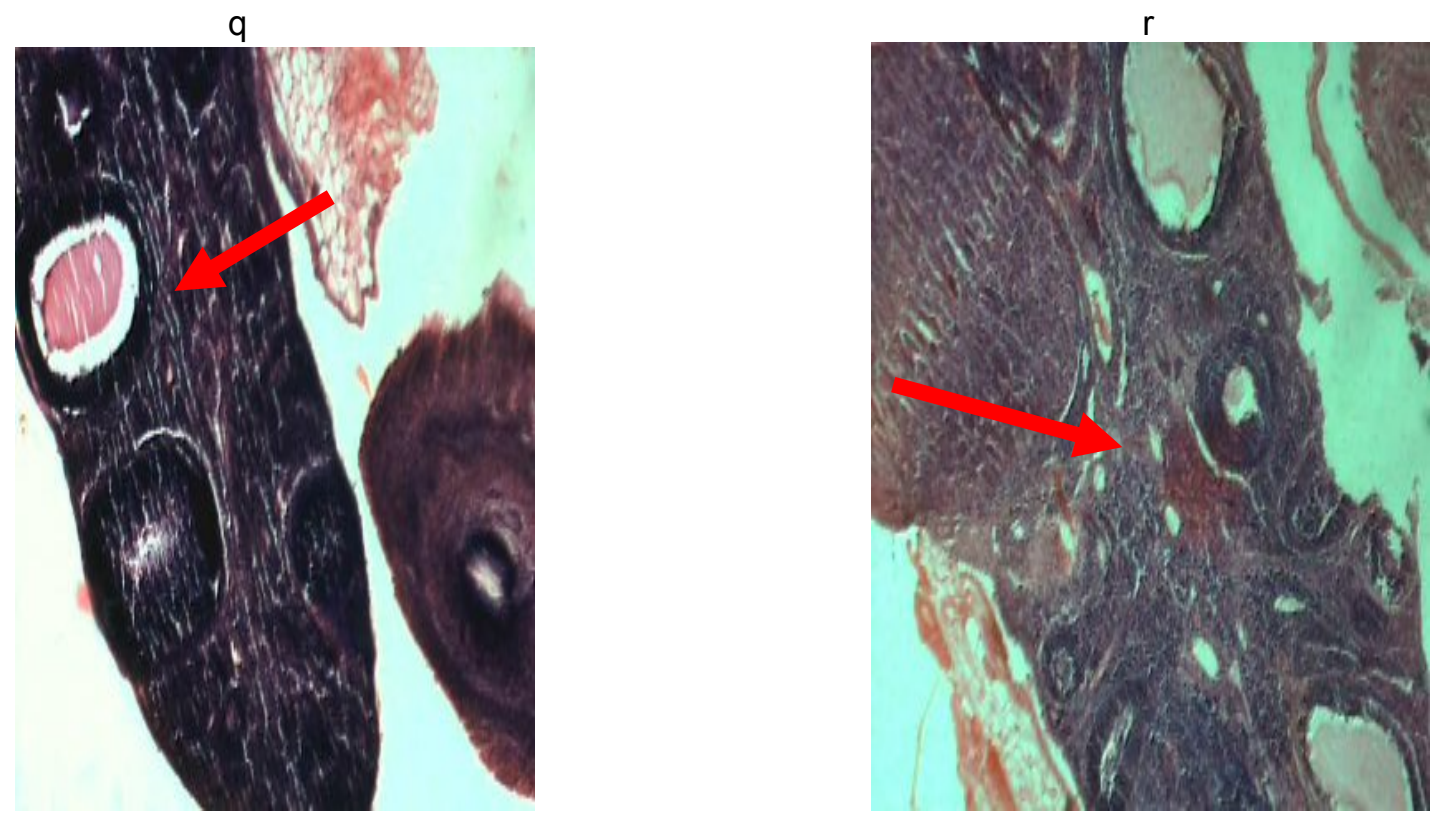

Plate 1q: Micrograph of the ovary in the in the group exposed to SAR $0.48 \mathrm{~W} / \mathrm{kg}$ showing thick sectioning coarse chomatin and oedema

Plate 1r: Micrograph of the ovary in the in the group exposed to SAR $0.95 \mathrm{~W} / \mathrm{kg}$ containing few follicles of varying sizes $\mathrm{H}$ and $\mathrm{E}$ stain Mag. $\mathrm{x} 40$
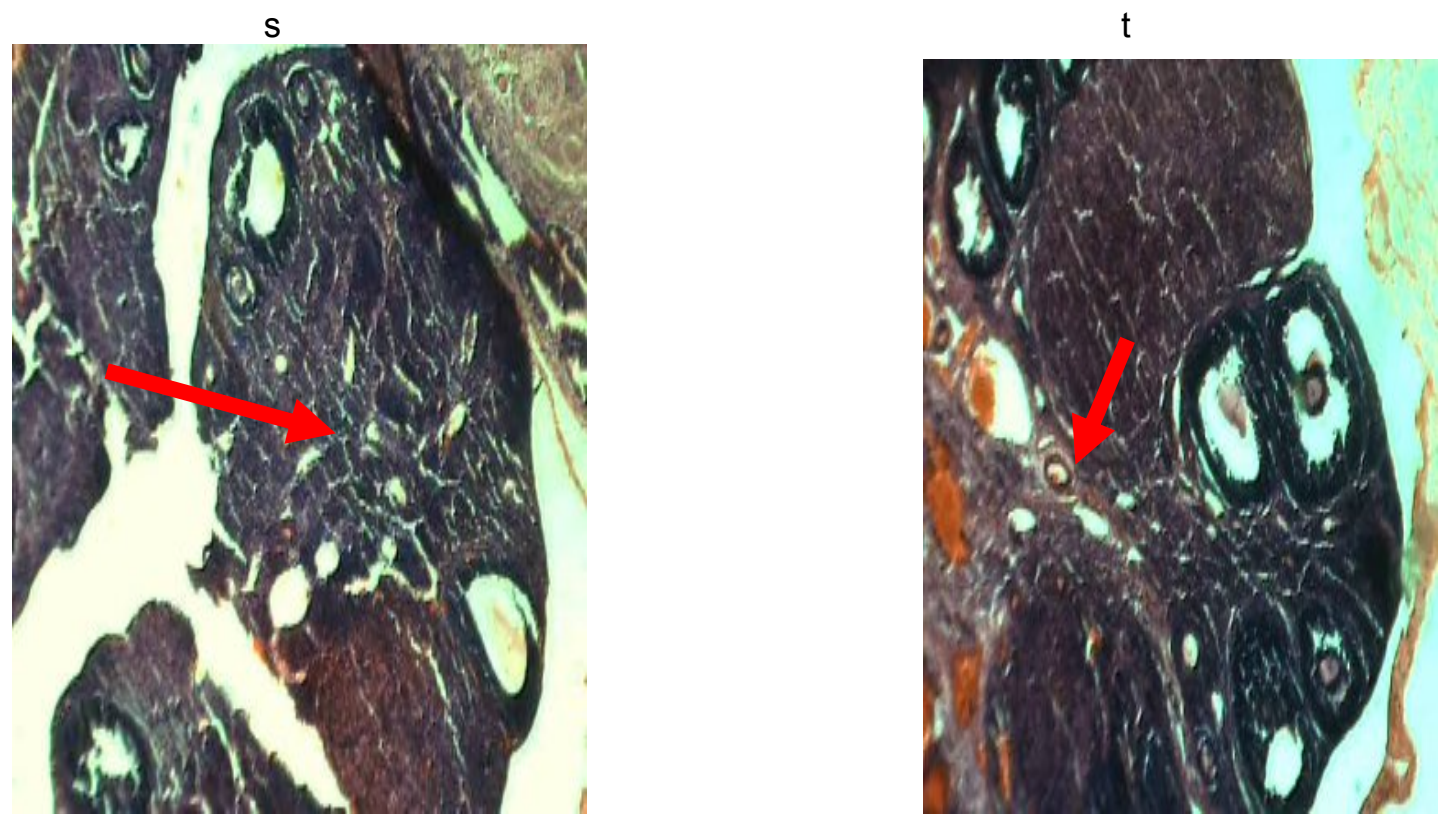

Plate 1s: Micrograph of the ovary in the group exposed to SAR $1.43 \mathrm{~W} / \mathrm{kg}$ showing increased, hyperchomasia coarse nuclear chomatin and cellular oedema

Plate 1t: Micrograph of the ovary in the group exposed to SAR $1.91 \mathrm{~W} / \mathrm{kg}$ showing vascular congestion cellular oedema and hyperchomatism in some of the follicles $\mathrm{H}$ and $\mathrm{E}$ stain Mag. $\mathrm{x} 40$ 
Am. J. Sci. Ind. Res., 2010, 1(3): 410-420

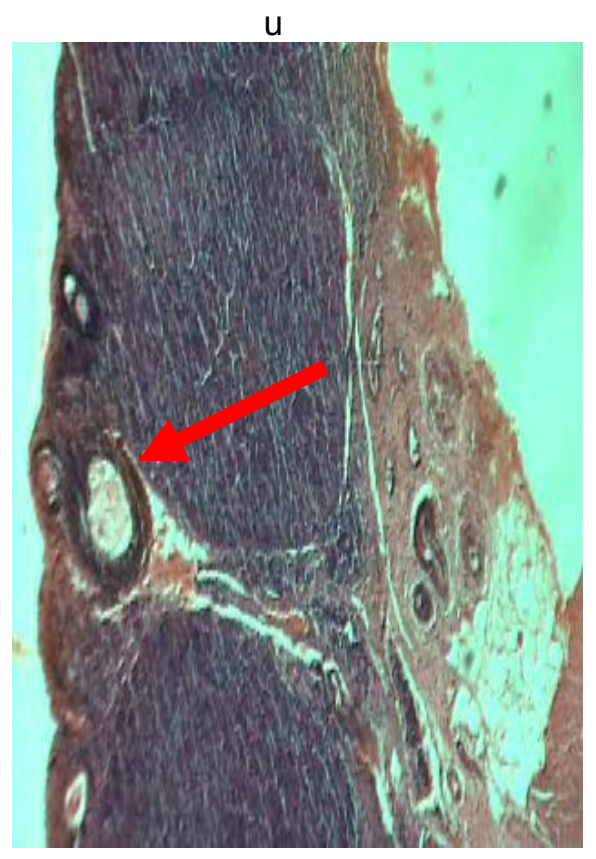

Plate 1u: Micrograph of the ovary in the group exposed exposed to SAR $2.39 \mathrm{~W} / \mathrm{kg}$ showing cellular Hyperchomatic granulocer cell and oedema $\mathrm{H}$ and $\mathrm{E}$ stain Mag. $\mathrm{x} 40$

\section{REFERENCES}

1. Anderson, L. E., Sheen D. M., Wilson, B. W., Grumbein, S. L., Creim, J. A. and Sasser, L.B.: Two-Year Chronic Bioassay Study of Rats Exposed to a $1.6 \mathrm{GHz}$ Radiofrequency Signal, Radiation Research 162, 201-210 (2004)

2. Aweda, M.A., Gbenebitse, S., Meidinyo, R.O.: Effects of $2.45 \mathrm{GHz}$ microwave exposures on the Peroxidation status in wistar rats. The Nigerian Postgraduate Medical Journal 10(4), 243 -246 (2003)

3. Aweda, M.A., Usikalu, M.R. and Awobajo, F.O.: Effects of $2.45 \mathrm{GHz}$ microwave radiation exposure on male reproductive functions in spagrue dawley rats. International Journal of Radiation Biology, in press (2010).

4. Barnes, F.S. and Hu, C.J.: Nonlinear interactions of electromagnetic waves with materials (in P.L.E. Usilenghi, ed.) New York Academic Press. 47-80 (1980)

5. Bernhardt, J.: The direct influence electromagnetic fields on nerve and muscle cells of man within the frequency range of $1 \mathrm{~Hz}$ to $30 \mathrm{MHz}$. Radiation and Environmental Biophysics 16, 309-323 (1979)

6. Bernhardt, J.H.: Hazards to human health from electromagnetic fields. Neuherberg, Dreimer Verlag, STH-Berichte Nr. 2. (1983)

7. Bren, S.P.A.: Historical introduction to electromagnetic field health effects. IEEE Engineering in Medicine and Biology 15, 41-44 (1996)

8. Canadian Council of Animal Care: Guide to the handling and use of experimental animals. Ottawa Ontario 2 (1985)

9. Dumey, C.H., Iskander, M.F., Massoudi, H., Allen, S.J. and Mitchell, J.C.: Radiofrequency radiation dosimetry handbook, $2^{\text {nd }}$ ed. Brooks Air Force Base, Texas, USAF School of Aerospace Medicine, Report SAM-TR-78-22 (1980)

10. Edwards, G.S.: Resonant microwave absorption of selected DNA molecules. Physical Review Letters 53, 1284-1287 (1984)

11. Foster, K.R.: Resonances in the dielectric absorption of DNA? Journal of Biophysics 52, 421-425 (1987)

12. Frei, M. R., Berger, R.E., Dusch, S. J., Guel, V., Jauchem, J. R., Merritt, J. H. and Stedham, M. A.: Chronic Exposure of Cancer-Prone Mice to LowLevel $2450 \mathrm{MHz}$ Radiofrequency Radiation, Bioelectromagnetics 19, 20-30 (1998b)

13. Gabril, C.: Microwave absorption in aqueous solution of DNA. Nature 328, 145-146 (1987)

14. J.E. Moulder, L.S. Erdreich, R.S. Malyapa, J. Merritt, W.F. Pickard, Vijayalaxmi: Cell phones and cancer: 
what is the evidence for connection? Radiat. Res. 151, 513-531 (1999)

15. Johnson, F.H., Eyring, H. and Staver, B.J.: The theory of rate processes in Biology and Medicine. New York; John Wiley 68-102 (1974)

16. Lyle, D.B., Schechter, P., Adey, W.R. and Lundak R.L.: Suppression of T-lymphocyte cytotoxicity following exposure to sinusoidally amplitudemodulated fields. Bioelectromagnetics 4, 281-292 (1983)

17. McRee, D.T. and Davies, H.: Wholebody and local dosimetry in rats exposed to $2.45 \mathrm{GHz}$ radiation. Health Physics 6(40), 315 (1984)

18. Pickard, W.F. and Rosenbaum, F.J.: Biological effects of microwaves at the membrane levels. Two possible athermal electro physiological mechanisms and a proposed experimental test. Mathematical Biosciences 39, 235-253 (1978)

19. Seaman, R.L. and Wachtel, H.: Slow and rapid responses to $\mathrm{CW}$ and pulsed microwave radiation by individual aplysia pacemakers. Journal of Microwave Power 13, 77-86 (1978)

20. Shandala, M.A.: Patterns of change in behavioural reactions to low power densities of microwave.
Abstracts, International symposium on the Biological Effects of Electromagnetic waves (URSI), Airlie, VA (1977)

21. Swicord, M. and Poscow, E.: Handbook of biological effect of electromagnetic radiation. Boca Raton, FI, CRC Press (1986)

22. Takashima, S.: Effects of modulated RF energy on the EEG of mammalian brains. Radiation and Environmental Biophysics 16, 15-27 (1979)

23. United States National Institutes of health $(\mathrm{NIH})$ publication, 85: 23

24. Utteridge, T. D., John, V. G., Vernon-Roberts, F. B.

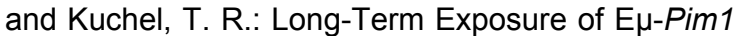
Transgenic Mice to $898.4 \mathrm{MHz}$ Microwaves does not Increase Lymphoma Incidence, Radiation Research 158, 357-364 (2002)

25. Yariv, A.: Optical Electronics. Holt, Rinehart and Wiston, New York (1985)

26. Zook, B.C. and Simmens, S. J.: The Effects of 860 $\mathrm{MHz}$ Radiofrequency Radiation on the Induction or Promotion of Brain Tumors and Other Neoplasms in Rats. Radiation Research 155, 572-583 (2001) 